\title{
Optics and Photonics for Homeland Security
}

\author{
Bahram Javidi, FELLOW SPIE \\ University of Connecticut \\ Department of Electrical and Computer \\ Engineering \\ Storrs, Connecticut 06269-2157 \\ E-mail: bahram@engr.uconn.edu
}

This issue of Optical Engineering marks an important first special section devoted to the topic of Optics and Photonics for Homeland Security. Optical and photonic systems and devices have significant potential for homeland security. The field of optical security has been around for many years, from the days of watermarks and intaglio printing. With rapid advances in technology, such as the laser, sensors, holograms, and digital electronics, the role of optics and photonics technologies for homeland defense and security will further advance. Unfortunately the same technical advances may fuel an increase in fraud and counterfeiting. For example, the problems with fraud and counterfeiting continue with the increase in digital technology and improvements in low-cost devices such as CCD sensors and color printers.

The interest by government, industry, and academia in the area of optics and photonics for homeland security has grown substantially over the past few years. Therefore, there is a growing need for venues to present technical advances in the field in the form of proceedings of conferences, special issues of journals, and books. SPIE has created a new Technical Group on Global Homeland Security (www.spie.org/membership), which meets regularly at SPIE meetings. The Springer Verlag publishing company (www.springeronline.com) has created a new series on Advanced Sciences and Technologies for Security Applications. The Optical Society of America and IEEE have held meetings on this topic.

In addition, there are numerous symposia, workshops, and conferences in this field including the SPIE Defense and Security Symposium, which meets in Orlando, and the European Symposium on Optics and Photonics in Defence and Security, which will meet in London this year. Generally, these meetings are very well attended with significant technical contributions from industry, government, and academia in the field of optical and photonic systems and devices, and imaging systems and image processing techniques for detection, identification, prevention, sensing, security, biometric techniques, verification, and anticounterfeiting.

While the state of technology has certainly advanced, it is generally agreed that much more R\&D in these fields are needed. From biometrics sensors and recognition systems to countering weapons of mass destruction, optics and photonics can play a substantial role in this rapidly growing field.

This special section contains a wide sampling of papers from many aspects of this field. This includes optical sensors, 3-D imaging, remote sensing, encryption techniques, biometric systems, secure bar codes, object recognition, and papers on fabrication, testing, and evaluation of actual verification and authentication systems. We hope the readers will be inspired by these articles to try and adapt their own areas of technical competency to this important field.

I wish to thank the authors for their fine contributions, the reviewers for their time and effort in refereeing the manuscripts, Prof. Donald O'Shea for giving me the opportunity to be the guest editor of this special section, and Ms. Karolyn Labes and the SPIE editorial staff for their assistance and patience in putting together this special section.

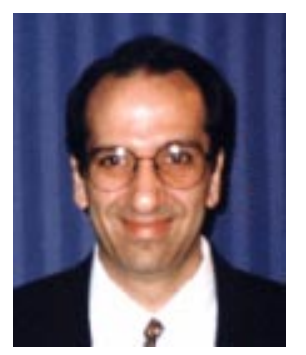

Bahram Javidi is a Board of Trustees Distinguished Professor of Electrical and Computer Engineering at the University of Connecticut. Dr. Javidi is a fellow of the Institute of Electrical and Electronics Engineers (IEEE), the Optical Society of America, and SPIE-The International Society for Optical Engineering. He received the IEEE Lasers and Electrooptics Society Distinguished Lecturer Award in 2003. He was the recipient of the IEEE Best Journal Paper Award from IEEE Transactions on Vehicular Technology in 2002. He has been awarded the University of Connecticut Alumni Association Excellence in Research Award, the Chancellor's Research Excellence Award, and the first Electrical and Computer Engineering Department Outstanding Research Award. Dr. Javidi has completed several books including Optical and Digital Techniques for Information Security, published by Springer in 2003; Image Recognition: Algorithms, Systems, and Applications, published by Marcel Dekker in 2002; Three Dimensional Television, Video, and Display Technologies, published by Springer Verlag in 2002; Smart Imaging Systems, published by SPIE Press in 2001; Real-time Optical Information Processing, published by Academic Press in 1994; and Optical Pattern Recognition, published by SPIE Press in 1994. He has published over 170 technical articles in major journals, including Physics Today and Nature, and his research has been cited in IEEE Spectrum, Science, and New Scientist. Dr. Javidi received the BS degree in electrical engineering from George Washington University, and the MS and PhD degrees in electrical engineering from the Pennsylvania State University. 